\title{
The influence of spinopelvic parameters on adjacent-segment degeneration after short spinal fusion for degenerative spondylolisthesis
}

\author{
*Ming-Kai Hsieh, MD, Fu-Cheng Kao, MD, Wen-Jer Chen, MD, PhD, I-Jung Chen, MD, MPH, and \\ Sheng-Fen Wang, MD
}

\begin{abstract}
Department of Orthopaedic Surgery, Spine Section, Bone and Joint Research Center, Chang Gung Memorial Hospital and Chang Gung University College of Medicine, Taoyuan, Taiwan
\end{abstract}

\begin{abstract}
OBJECTIVE Spinopelvic parameters, such as the pelvic incidence (PI) angle, sacral slope angle, and pelvic tilt angle, are important anatomical indices for determining the sagittal curvature of the spine and the individual variability of the lumbar lordosis (LL) curve. The aim of this study was to investigate the influence of spinopelvic parameters and LL on adjacent-segment degeneration (ASD) after short lumbar and lumbosacral fusion for single-level degenerative spondylolisthesis.

METHODS The authors retrospectively reviewed the records of all short lumbar and lumbosacral fusion surgeries performed between August 2003 and July 2010 for single-level degenerative spondylolisthesis in their orthopedic department.

RESULTS A total of 30 patients (21 women and 9 men, mean age 64 years) with ASD after lower lumbar or lumbosacral fusion surgery comprised the study group. Thirty matched patients (21 women and 9 men, mean age 63 years) without ASD comprised the control group, according to the following matching criteria: same diagnosis on admission, similar pathologic level ( $\leq 1$ level difference), similar sex, and age. The average follow-up was 6.8 years (range $5-8$ years). The spinopelvic parameters had no significant influence on ASD after short spinal fusion.
\end{abstract}

CONCLUSIONS Neither the spinopelvic parameters nor a mismatch of $\mathrm{PI}$ and LL were significant factors responsible for ASD after short spinal fusion due to single-level degenerative spondylolisthesis.

https://thejns.org/doi/abs/10.3171/2018.2.SPINE171160

KEYWORDS pelvic incidence; pelvic tilt; sacrum slope; degenerative spondylolisthesis; adjacent-segment instability

$\mathrm{T}$ HE long-term clinical outcomes of spinal fusion in degenerative spondylolisthesis are influenced by a variety of pathophysiological factors such as the recurrence of spinal canal stenosis, instability, lumbar kyphosis, nonunion, and adjacent-segment degeneration (ASD). ${ }^{15}$ The risk factors for ASD after short spinal fusion for degenerative spondylolisthesis include the aging process, sacrifice of the posterior ligament complex, excessive decompression during surgery, and poor sagittal balance after lumbar fusion. ${ }^{7}$ Over the past 15 years, sagittal balance analysis has gained importance in reconstructive surgery of the spine. ${ }^{6,21}$ With the increasing use of vertebral fusion, deteriorative effects of surgery on sagittal balance have been reported. ${ }^{14}$ These effects on sagittal balance are related to the locked position of the fused vertebra; the consequence of fixed sagittal imbalance is a loss of normal lumbar curvature, with forward inclination of the trunk..$^{8,9}$

Use of the $\mathrm{C} 7$ plumb line, defined as a line dropped from the center of the $\mathrm{C} 7$ vertebra, is the most common method of identifying risk and prognosis associated with sagittal balance. ${ }^{21}$ The horizontal distance from the posterosuperior corner of the sacrum to the plumb line is recorded as the magnitude of the sagittal vertical axis (SVA), and the degree of the SVA indicates sagittal balance.18

ABBREVIATIONS ASD = adjacent-segment degeneration; $L L=$ lumbar lordosis; $\mathrm{PI}=$ pelvic incidence; $\mathrm{PT}=$ pelvic tilt; $\mathrm{SS}=$ sacral slope; SVA = sagittal vertical axis; VAS = visual analog scale.

SUBMITTED October 23, 2017. ACCEPTED February 28, 2018.

INCLUDE WHEN CITING Published online July 20, 2018; DOI: 10.3171/2018.2.SPINE171160.

${ }^{*}$ M.K.H. and W.J.C. contributed equally to this work. 
Measurement of the $\mathrm{C} 7$ plumb line for evaluation of the SVA is often difficult and several studies have shown that pelvic parameters, especially the pelvic incidence (PI) angle, are an indirect method of checking sagittal balance. . $^{3,19}$ Spinopelvic parameters, such as the PI, sacral slope (SS) angle, and pelvic tilt (PT) angle, are important morphological and positional indices for determining the sagittal curvature of the spine and the individual variability of the lumbar lordosis (LL) curve.

Our aim is to investigate the influence of spinopelvic parameters and LL on ASD after short lumbar or lumbosacral fusion for single-level degenerative spondylolisthesis.

\section{Methods \\ Study Population}

Between August 2003 and July 2010, a retrospective database review was conducted to identify all patients who underwent short lumbar or lumbosacral fusion surgeries ( $\leq 2$ levels) for single-level degenerative spondylolisthesis. All procedures were performed in the spine section of our orthopedic department. Inclusion criteria included primary spinal operations with short spinal fusion and decompression ( $\leq 2$ levels) due to single-level degenerative spondylolisthesis. No revision surgery was performed except for the ASD during the follow-up period.

Patients were excluded due to scoliosis more than $10^{\circ}$; preexisting disc degeneration of adjacent segments before primary surgery; anterior spine surgery; and preoperative vertebral compression fracture of the lumbar spine. During the study period, patients enrolled had to have a minimum follow-up period of 5 years and were divided into ASD and non-ASD groups. Radiographic criteria were used to define ASD: development of spondylolisthesis $\geq 4 \mathrm{~mm}$, segmental instability $\geq 10^{\circ}$ on dynamic views, disc degeneration change of more than 1 grade according to the University of California at Los Angeles Grading Scale, ${ }^{12}$ and disc degeneration of Modic type 2 or 3 (Fig. 1). A pairwise, retrospective, case-control study with 1-to-1 matching was performed between these two groups. Thirty patients were randomly selected from the ASD group as the study group.

A computer-generated list of potential controls was obtained from the non-ASD group database with a minimum follow-up period of 5 years. Controls were chosen according to the following matching criteria: same diagnosis on admission, similar pathologic level ( $\leq 1$ level difference), similar sex, and similar age. The list of potential controls was reviewed for the best possible match, giving priority to diagnosis and similar pathological level, sex, and age. When multiple possible controls existed to match 1 case, the patient with the date of admission closest to that of the study patient was selected.

\section{Data Collection}

Medical records, imaging studies, laboratory data, neurological function data, and functional outcomes were reviewed and analyzed. Standard standing radiographs, including lumbosacral anterior-posterior, lateral, and dynamic views were obtained preoperatively, postoperatively (within 2 weeks after the operations), and at the last follow-up. A single investigator checked the status of ASD and measured the degrees of LL angle, SS angle, PT angle, and PI angle, using standard lumbosacral lateral and dynamic views. SS is the angle between the horizontal line and the orientation of the sacral plateau. LL is defined using the Cobb L1-S1 method: the angle between the superior endplates of L1 and S1. PT is the angle between the vertical line through the femoral head and a line from the midsacral plateau and femoral head. By drawing a line through the center of the sacral plateau to that of the femoral head, this line and the perpendicular line dropped from the sacral plateau form the PI (Fig. 2).

Clinical outcomes were evaluated using patient-assessed quantitative measurements including a visual analog scale (VAS) for axial back pain as well as leg pain, and the Oswestry Disability Index. All procedures performed in studies involving human participants were in accordance with the ethical standards of the institutional and/ or national research committee and with the $1964 \mathrm{Hel}-$ sinki declaration and its later amendments or comparable ethical standards. The Chang Gung Medical Foundation IRB approved this study and waived the requirement for informed consent due to the retrospective nature of the study.

\section{Statistical Analysis}

A statistical software program (SPSS for Windows, version 12.0; SPSS Inc.) was used to analyze the preoperative and postoperative parameters in both groups. All data were presented as means \pm standard deviations. The differences between the study and control groups in spinopelvic parameters and LL were evaluated using Fisher's exact test and Mann-Whitney U-test analyses. The clinical and spinopelvic parameters were compared at preoperative, postoperative, and follow-up time points. Multivariate analysis was performed using logistic multiple regression analysis. Statistical significance for all tests was set at a $\mathrm{p}$ value of 0.05 .

\section{Results}

Between August 2003 and July 2010, a total of 978 patients with single-level degenerative spondylolisthesis who underwent short-segment spinal fusion were enrolled in this study. Patients underwent primary spine surgeries using the traditional midline open method with pedicle screw fixation as well as posterolateral fusion, interbody fusion, or both. Three hundred seventy-two patients were excluded who had less than 5 years follow-up. From the remaining 606 patients, 266 patients (43.9\% of the patients with more than 5 years of follow-up) were defined as the ASD group and the other 340 patients $(56.1 \%)$ were categorized as the non-ASD group. Thirty randomly selected patients (21 women and 9 men, mean age 64 years) in the ASD group made up the study group. Of those 30 study group patients, 6 patients underwent revision surgery due to symptomatic adjacent problems. Ten percent of the patients (20\% of patients in the study group) underwent revision surgery due to symptomatic ASD problems with an average duration of 51.2 months.

The control group was chosen from the non-ASD 
Hsieh et al.
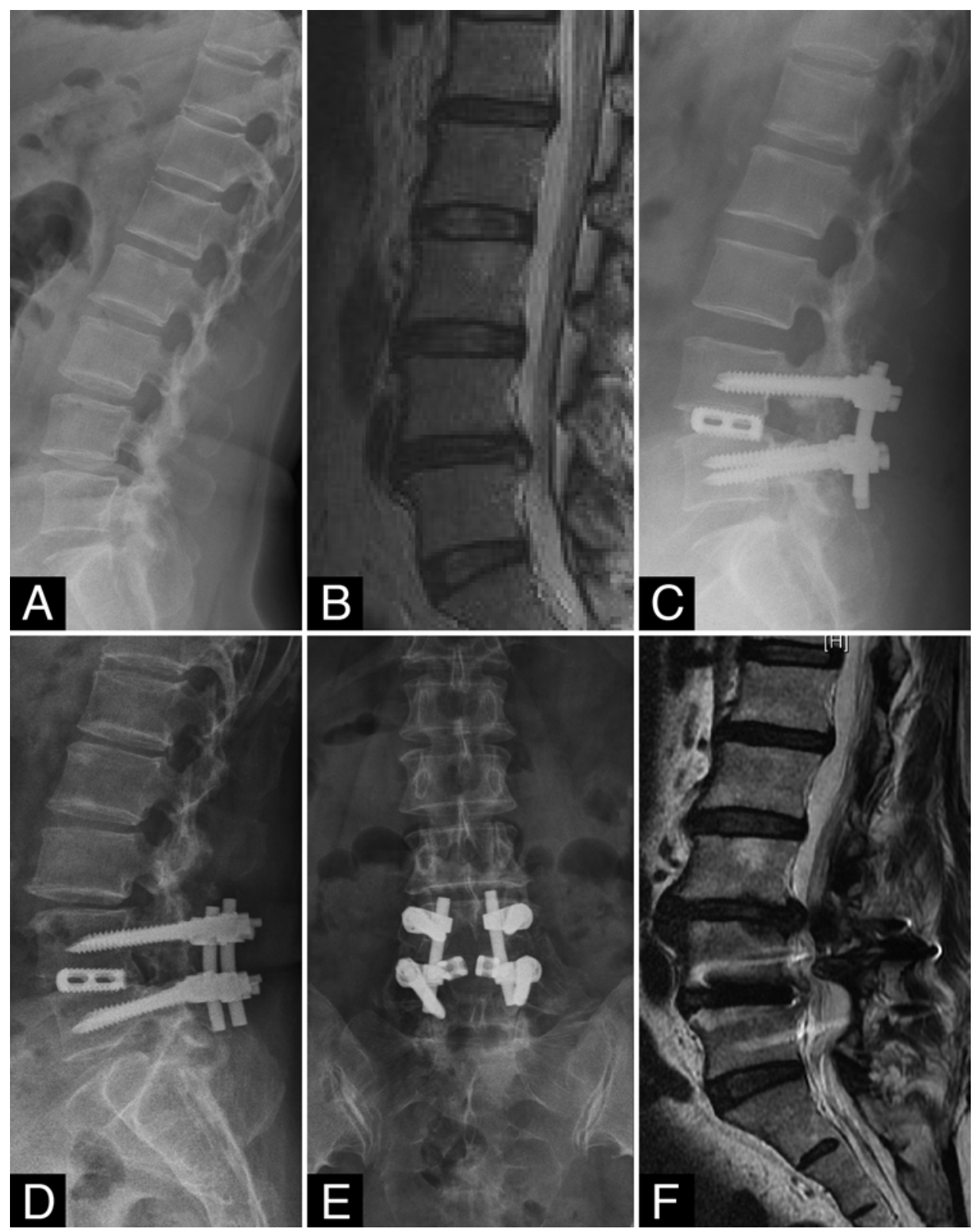

FIG. 1. A 60-year-old woman was diagnosed preoperatively with degenerative spondylolisthesis and lumbar spinal stenosis at the L4-5 level, as shown on radiography (A) and a T2-weighted MR image (B). She underwent posterior instrumentation and interbody fusion at L4-5 with immediate postoperative radiography (C). Five years after surgery, she was diagnosed with ASD at the L3-4 level with adjacent spondylolisthesis, spinal stenosis, and disc degeneration as seen on radiographs (D and E) and a T2-weighted MR image (F).

group according to the following matching criteria (i.e., 1-to-1 matching to the study group): same diagnosis on admission, similar pathologic level ( $\leq 1$ level difference), sex, and age. The average follow-up period for both study and control groups was 6.8 years (range $5-8$ years). Clinical and surgical data are shown in Table 1. Comparisons of LL and spinopelvic parameters (PI, PT, SS, and PI-LL mismatch between preoperative, immediate postoperative, and last follow-up time points) are shown in Table 2. There was no statistically significant difference in preoperative symptoms (e.g., low-back pain, claudication, sciatica, or the duration), spondylolisthesis level, fusion length, LL, PI angle, PT angle, SS angle, and PI-LL mismatch between the study and control groups. The results remained the same after multivariate logistic regression analysis.

\section{Discussion}

The concept of "cone of economy," first introduced by Jean Dubousset in $1994,{ }^{11}$ refers to a stable condition regarding standing posture. Within the center of the cone, the energy spent in stance is minimized, resulting from 


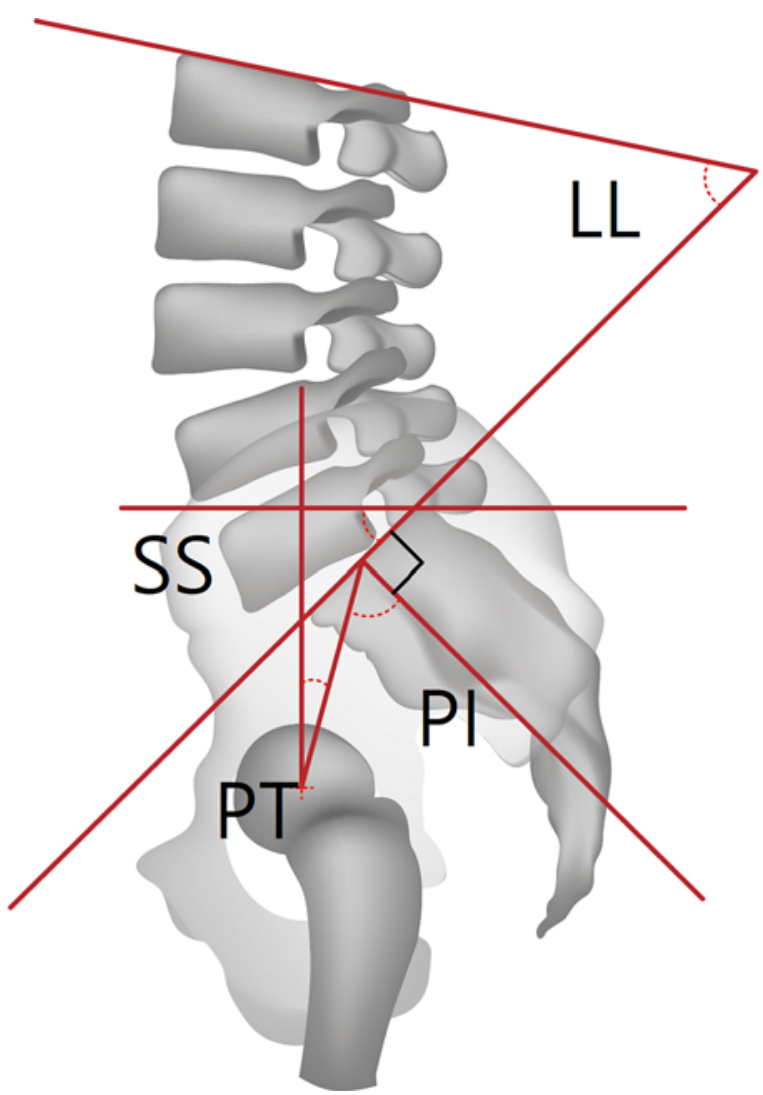

FIG. 2. Measurement of LL and spinopelvic parameters. SS is the angle between the horizontal line and the orientation of the sacral plateau. $\mathrm{LL}$ is defined using the Cobb L1-S1 method (the angle between the superior endplates of L1 and S1). PT is the angle between the vertical line through the femoral head and a line from the midsacral plateau and femoral head. By drawing a line through the center of the sacral plateau to that of the femoral head, this line and the perpendicular line dropped from the sacral plateau form the PI. Copyright Fu-Cheng Kao. Published with permission. Figure is available in color online only.

a complex integration of physiological alignment of the spine in the coronal and sagittal planes, intrinsic paraspinal musculature activation, bone morphology, and balanced tension of the spinal ligaments. Ideal spinal alignment of the human body is set to maintain the center of gravity within the cone of economy with an extended painfree and economical erect position. This requires precise interaction of spinal and spinopelvic parameters. Trunk imbalance is therefore the consequence when exceeding the center of the cone, and would cost further unnecessary energy spent to maintain one's standing position.

PI is the morphological parameter that plays a key role in the regulation of positional pelvic and spinal factors. ${ }^{3,29}$ The potential for variation of the spinal curves is associated with variation in pelvic positional parameters. For the same PI, SS and PT can vary, with the following relation among them: PI (morphological) $=$ SS $($ positional $)+$ PT (positional). ${ }^{20} \mathrm{SS}$ induces curves above the level of the pelvis, i.e., the spinal curves, and PT induces factors below the level of the pelvis, i.e., the angle of the coxofemoral joints in the upright posture. PI creates different lordosis
TABLE 1. Clinical and surgical data of all patients

\begin{tabular}{lccc}
\hline \multicolumn{1}{c}{ Variable } & $\begin{array}{c}\text { Study } \\
\text { Group }\end{array}$ & $\begin{array}{c}\text { Control } \\
\text { Group No. } \\
(\%)\end{array}$ & $\begin{array}{c}p \\
\text { Value }\end{array}$ \\
\hline Males/females, $\mathrm{n}(\%)$ & $9 / 21(30 / 70)$ & $9 / 21(30 / 70)$ & 1.000 \\
\hline Mean age \pm SD, yrs & $64 \pm 8.68$ & $63 \pm 10.05$ & 0.505 \\
\hline Back pain, $\mathrm{n}(\%)$ & $30(100.0)$ & $29(96.7)$ & 1.000 \\
\hline $\begin{array}{l}\text { Mean back pain duration } \pm \text { SD, } \\
\text { mos }\end{array}$ & $12 \pm 8.94$ & $14 \pm 11.39$ & 0.958 \\
\hline Leg pain, $\mathrm{n}(\%)$ & $29(96.7)$ & $30(100.0)$ & 1.000 \\
\hline Mean leg pain duration \pm SD, mos & $11 \pm 9.37$ & $12 \pm 11.66$ & 0.607 \\
\hline Claudication, $\mathrm{n}(\%)$ & $27(90.0)$ & $25(83.3)$ & 0.706 \\
\hline Spondylolisthesis level, $\mathrm{n}(\%)$ & & & 0.661 \\
\hline L3-4 & $6(20)$ & $8(27)$ & \\
\hline L4-5 & $23(77)$ & $20(67)$ & \\
\hline L5-S1 & $1(3)$ & $2(7)$ & \\
\hline Fusion level, $\mathrm{n}(\%)$ & & & 0.718 \\
\hline 1 & $25(83)$ & $26(87)$ & \\
\hline 2 & $5(17)$ & $4(13)$ & \\
\hline Mean preop VAS score \pm SD & & & \\
\hline Back pain & $8 \pm 0.82$ & $8 \pm 0.74$ & 0.465 \\
\hline Leg pain & $8 \pm 1.52$ & $8 \pm 1.00$ & 0.731 \\
\hline Mean postop VAS score \pm SD & & & \\
\hline Back pain & $2 \pm 0.52$ & $2 \pm 0.63$ & 0.619 \\
\hline Leg pain & $1 \pm 0.50$ & $1 \pm 0.49$ & 0.601 \\
\hline
\end{tabular}

values to allow conditions conducive to standing posture and gait, according to the principle of biomechanical economy. Every individual has his or her own standard and appropriate lordosis value. The lordosis assigned to the morphological pelvis, evaluated by PI (which determines the spine and pelvis positional parameters, LL $=$ $\mathrm{PI} \pm 9^{\circ}$ ), determines the predicted (theoretical) lordosis. ${ }^{17}$

Spinal arthrodesis with instrumentation has become a widely used treatment for spinal instability nowadays. After rigid fixation and solid spinal fusion, adjacent loading stress in mobile segments changes, causing adjacentsegment diseases in patients postoperatively, which is now considered one of the common long-term complications. In our study, radiographic ASD was found in $43.8 \%$ of total patients. In other papers that have conducted this review, an incidence rate more than $30 \%$ was reported for radiographic $\mathrm{ASD},{ }^{5}$ and there were several risk factors for its development. Fusion length, decompression level, facet capsule violation, and alignment of fusion level were considered as surgical factors, causing higher risk in developing postoperative ASD. Beyond surgical factors, patient factors, however, were strongly related to diathesis of each patient and could not be modified during the operations. Older age, the medical condition of obesity, menopause, preexisting ASD, and the morphology of pelvic inclination were patient factors found to be related to postoperative ASD. ${ }^{30}$ However, in our study, there was no statistically significant difference in age, sex, preoperative symptoms, level of spondylolisthesis, length of fusion, or decompres- 
TABLE 2. Difference of spinopelvic parameters between the two groups

\begin{tabular}{|c|c|c|c|}
\hline Parameter & Study Group & $\begin{array}{l}\text { Control } \\
\text { Group }\end{array}$ & $\begin{array}{c}p \\
\text { Value }\end{array}$ \\
\hline \multicolumn{4}{|l|}{ Preop } \\
\hline SS & $33^{\circ} \pm 10.51^{\circ}$ & $32^{\circ} \pm 11.60^{\circ}$ & 0.610 \\
\hline $\mathrm{PI}$ & $54^{\circ} \pm 12.51^{\circ}$ & $53^{\circ} \pm 11.58^{\circ}$ & 0.982 \\
\hline PT & $21^{\circ} \pm 9.03^{\circ}$ & $22^{\circ} \pm 11.62^{\circ}$ & 0.871 \\
\hline $\mathrm{LL}$ & $48^{\circ} \pm 11.74^{\circ}$ & $47^{\circ} \pm 16.28^{\circ}$ & 0.918 \\
\hline No. w/ PI-LL mismatch, $\geq 10^{\circ}$ & $14(46.7 \%)$ & $13(43.3 \%)$ & 0.795 \\
\hline \multicolumn{4}{|l|}{ Immediate postop } \\
\hline SS & $32^{\circ} \pm 8.76^{\circ}$ & $30^{\circ} \pm 8.23^{\circ}$ & 0.657 \\
\hline $\mathrm{PI}$ & $54^{\circ} \pm 12.51^{\circ}$ & $53^{\circ} \pm 11.58^{\circ}$ & 0.982 \\
\hline PT & $22^{\circ} \pm 9.24^{\circ}$ & $23^{\circ} \pm 10.70^{\circ}$ & 0.807 \\
\hline $\mathrm{LL}$ & $42^{\circ} \pm 11.02^{\circ}$ & $42^{\circ} \pm 12.28^{\circ}$ & 0.935 \\
\hline No. w/ PI-LL mismatch, $\geq 10^{\circ}$ & $18(60.0 \%)$ & $17(56.7 \%)$ & 0.793 \\
\hline \multicolumn{4}{|l|}{ Last follow-up } \\
\hline SS & $33^{\circ} \pm 9.09^{\circ}$ & $32^{\circ} \pm 8.62^{\circ}$ & 0.929 \\
\hline PI & $54^{\circ} \pm 12.51^{\circ}$ & $53^{\circ} \pm 11.58^{\circ}$ & 0.982 \\
\hline PT & $21^{\circ} \pm 10.03^{\circ}$ & $21^{\circ} \pm 12.15^{\circ}$ & 0.767 \\
\hline LL & $45^{\circ} \pm 14.19^{\circ}$ & $47^{\circ} \pm 11.99^{\circ}$ & 0.636 \\
\hline No. w/ PI-LL mismatch, $\geq 10^{\circ}$ & $17(56.7 \%)$ & $16(53.3 \%)$ & 0.795 \\
\hline
\end{tabular}

All data given as mean \pm SD unless otherwise indicated.

sion between all groups. In addition, due to our highly selective criteria of single-level spondylolisthesis and only 1- or 2-level fusion, there was no preexisting degeneration of the adjacent disc in our population.

Spinopelvic harmony is a posture for individuals to maintain sagittal balance with minimal energy consumption in a stable standing position. To further precisely fulfill the concept of spinopelvic harmony in clinical practice, the following parameters are known to be maintained: SVA $<50 \mathrm{~mm}, \mathrm{PT}<20^{\circ}$, and $\mathrm{LL}=\mathrm{PI} \pm 9^{\circ} .{ }^{26}$ Aoki et al. stated that postoperative PI-LL mismatch causes greater residual low-back pain, and surgeons should pay attention to the sagittal spinopelvic balance even when treating spinal stenosis or spondylolisthesis. ${ }^{1}$ Rothenfluh et al. showed that, in degenerative disease of the lumbar spine, a high PI with a diminished LL appears to predispose a patient to ASD. Patients with such PI-LL mismatch exhibit a 10-fold higher risk of undergoing revision surgery if sagittal malalignment is maintained after lumbar fusion surgery. ${ }^{23} \mathrm{~Pa}-$ tients with PI-LL mismatch are at a higher risk for sagittal imbalance; they are therefore treated using other spinal parameters for compensation, which may lead to increased rates of ASD. In our study, there was no significant difference in the PI-LL mismatch rate in preoperative, immediate postoperative, and last follow-up observation between the study and control groups. However, the study group included patients with only radiographic ASD and patients who underwent revision spine surgery. This might be the reason that PI-LL mismatch did not achieve statistical significance in our study as it did in previous studies.

The PT is also an important factor influencing spinal alignment and adjacent-segment disease. According to a study conducted by Di Martino et al., patients with a PT greater than $20^{\circ}$ and an SS less than $40^{\circ}$ fall into a higher-risk group for clinically evident ASD and subsequent reintervention. Pelvic retroversion and hypolordosis are the two main mechanisms of compensation that create an unbalanced spine..$^{10}$ Yamasaki et al. found greater PT results with decreased LL, flexion contracture of the hip and knee, and nerve or muscle disorders. Compensatory pelvic retroversion restores a mechanically efficient posture; the risk of ASD is 5.1 times greater in patients with a preoperative PT more than $22.5^{\circ} .{ }^{32}$ In our study, there was no statistical difference in PT or LL at preoperative, immediate postoperative, and last follow-up observation between the study and control groups.

In a study conducted by Barrey et al., loss of lordosis was more common in patients with a lower PI. When patients experience loss of lordosis, a significant anterior displacement of the $\mathrm{C} 7$ plumb line occurs. ${ }^{2}$ Loss of lordosis is not only structural, secondary to segmental discopathy and loss of disc height, but also postural, secondary to the posture the patient adopts to relieve pain and avoid posterior discal hyperpressure. This loss causes a predisposition to disc degeneration and pathologic change. Rajnics et al. showed that patients with disc herniation have a relatively straight spine in the sagittal plane, with a significant decrease in both LL and SS. ${ }^{22}$ An increased PI may lead to a higher contact force on the lower facet joints and cause facet joint arthritis, along with a more sagittal facet joint orientation. Individuals with an increased PI may therefore be at high risk for facet joint arthritis at the lower lumbar spine. ${ }^{16}$ A significantly greater pelvic incidence indicates that the shape of the pelvis is a main predisposing factor for degenerative spondylolisthesis. ${ }^{2}$ In the normal population, a high PI is usually associated with a pronounced SS and more LL. ${ }^{24}$ The degree of lordosis noted in these patients generates forces on the posterior articular joints and probably causes excessive mechanical stresses on the posterior facets, accelerating arthrosis change. According to our study, there is no correlation between the size of the PI and the incidence of ASD caused by short-segment spinal fusion, including disc degeneration, segmental instability, and spondylolisthesis.

In this case-control study, we did not report SVA for global spinal alignment assessment because of the retrospective nature of the study, as routine full-length spine radiography was not obtained in patients undergoing short lumbar spinal fusion surgery in our practice. Instead, we assessed spinopelvic parameters to investigate sagittal balance and its relationship to radiographic ASD in this retrospective study. In the general population, the PI angle measures approximately $54^{\circ}$ with a range from $34^{\circ}$ to $84^{\circ}$; the positional angles, SS and PT, measure approximately $40^{\circ}$ with a range of $20^{\circ}-65^{\circ}$ and $12^{\circ}$ with a range of $5^{\circ}-30^{\circ}$, respectively. ${ }^{27,28}$ Preoperatively, the patients in our study showed normal PI angles with decreased SS angles. Based on the study and classification system of Roussouly et al. ${ }^{24}$ that identified sagittal alignment in a group of 160 asymptomatic individuals, most of our patients belonged to type I and type II with SS less than $35^{\circ}$ and a relatively short lordotic curve of the total thoracolumbar spine. The 
morphology of types I and II in the 4-part classification scheme revealed straighter lumbar curves with loss of lordosis in this type of patient. Thus, we found that the rate of PI-LL mismatch was high in both the study and control groups. Decreased LL could relieve excessive mechanical stress on the posterior facet joints, which avoids adjacent facet arthritis and lumbar foraminal stenosis..$^{22}$ It would also decrease clinical symptoms (such as sciatica and claudication) secondary to ASD and reduce the reoperation rate. Sixty-three patients underwent reoperation due to ASD with clinical symptoms in this retrospective study. The total reoperation rate was $10.4 \%$ in this cohort. Compared to the $14 \%$ reoperation rate in the SLIP (Spinal Laminectomy versus Instrumented Pedicle Screw) study, ${ }^{13}$ $11 \%$ in the SPORT (Spine Patient Outcomes Research Trial) study, ${ }^{31}$ and $13.3 \%$ in the study by Brodke et al., ${ }^{4}$ our reoperation rate was lower. Decreased SS and LL postoperatively was more likely to cause positive sagittal imbalance with a stooped posture. ${ }^{25}$ Patients would compensate for this sagittal imbalance by hip extension, knee flexion, and ankle dorsiflexion. The compensated posture caused early muscle fatigue and poor exercise tolerance. However, in clinical practice, it was very difficult to distinguish low-back and buttock pain from postoperative muscle fibrosis or sagittal imbalance, although low-back soreness and pain must have been mentioned during the follow-up. Reoperation usually would not be performed because of simple low-back soreness and pain without sciatica.

A study by Rothenfluh et al. ${ }^{23}$ reported that patients with high PI with diminished LL were predisposed to symptomatic ASD and a higher risk of undergoing reoperation. Higher PI would cause a relatively longer lordotic curve in the thoracolumbar spine ${ }^{24}$ and lead to a higher contact force on the adjacent facet joints, causing facet joint arthritis. ${ }^{16}$ Adjacent facet joint arthritis is the main factor causing ligamentum flavum and facet capsule hypertrophy. Therefore, the resulting spinal stenosis and foraminal stenosis would lead to neurological symptoms and higher risk of reoperation. In our study, most of the patients had relatively straight lumbar spines with normal PI and diminished LL. Axial weight loading was evenly distributed on the vertebral disc and lower contact force was on the adjacent facet joint in this kind of morphology. Our focus was on the radiographic change but not on the clinical symptoms. In addition, most patients underwent only single-level spinal fusion in this study. Due to our highly restrictive inclusion criteria, there was no preoperative scoliosis, preexisting disc degeneration of adjacent segments, or vertebral compression fracture in our patients. Preoperative spinal degeneration might be less severe in our patient population.

Our study had several limitations. It was a retrospective, case-controlled study conducted in a diverse population. Additionally, some patients were lost to follow-up due to the nature of the retrospective study, and randomized selection of the control group was not used, which increased the risk for selection bias. Our results differed from previous studies because our study group included both participants with only radiographic ASD and participants who underwent revision spine surgery for symptomatic ASD. The definition of ASD varies from study to study, not to mention the specific definition of radiographic ASD and clinical ASD. Patients with radiographic ASD may not have clinical ASD, and vice versa. Finally, observational bias may have resulted from intraobserver variability.

\section{Conclusions}

Spinopelvic parameters and mismatch of the PI and LL were not significant factors in the development of ASD after short spinal fusion performed for single-level degenerative spondylolisthesis. However, physiological curvature of the spine adopted for energy saving and pain relief is related to trunk balance and the spinopelvic parameters of PI, PT, and SS. Nonfused segments of the spine after short spinal fusion might compensate for the effect of the fused segments. Further studies related to radiographic and symptomatic ASD, such as the influence of spinopelvic parameters after long spinal fusion, the status of preexisting degeneration, preoperative thoracolumbar and spinopelvic morphology, and back muscle strength for compensation, are worth investigation.

\section{Acknowledgments}

We thank the Department of Orthopaedic Surgery for their contribution to the study. This work was supported by Chang Gung Memorial Hospital (grant No. CMRPG3F2051).

\section{References}

1. Aoki Y, Nakajima A, Takahashi H, Sonobe M, Terajima F, Saito M, et al: Influence of pelvic incidence-lumbar lordosis mismatch on surgical outcomes of short-segment transforaminal lumbar interbody fusion. BMC Musculoskelet Disord 16:213, 2015

2. Barrey C, Jund J, Noseda O, Roussouly P: Sagittal balance of the pelvis-spine complex and lumbar degenerative diseases. A comparative study about 85 cases. Eur Spine J 16:14591467,2007

3. Boulay C, Tardieu C, Hecquet J, Benaim C, Mouilleseaux B, Marty C, et al: Sagittal alignment of spine and pelvis regulated by pelvic incidence: standard values and prediction of lordosis. Eur Spine J 15:415-422, 2006

4. Brodke DS, Annis P, Lawrence BD, Woodbury AM, Daubs MD: Reoperation and revision rates of 3 surgical treatment methods for lumbar stenosis associated with degenerative scoliosis and spondylolisthesis. Spine (Phila Pa 1976) 38:2287-2294, 2013

5. Cheh G, Bridwell KH, Lenke LG, Buchowski JM, Daubs $\mathrm{MD}, \mathrm{Kim}$ Y, et al: Adjacent segment disease following lumbar/thoracolumbar fusion with pedicle screw instrumentation: a minimum 5-year follow-up. Spine (Phila Pa 1976) 32:2253-2257, 2007

6. Chen LH, Lai PL, Tai CL, Niu CC, Fu TS, Chen WJ: The effect of interspinous ligament integrity on adjacent segment instability after lumbar instrumentation and laminectomyan experimental study in porcine model. Biomed Mater Eng 16:261-267, 2006

7. Chen WJ, Lai PL, Chen LH: Adjacent instability after instrumented lumbar fusion. Chang Gung Med J 26:792-798, 2003

8. Chen WJ, Lai PL, Niu CC, Chen LH, Fu TS, Wong CB: Surgical treatment of adjacent instability after lumbar spine fusion. Spine (Phila Pa 1976) 26:E519-E524, 2001

9. Chen WJ, Lai PL, Tai CL, Chen LH, Niu CC: The effect of sagittal alignment on adjacent joint mobility after lumbar 
instrumentation - a biomechanical study of lumbar vertebrae in a porcine model. Clin Biomech (Bristol, Avon) 19:763768, 2004

10. Di Martino A, Quattrocchi CC, Scarciolla L, Papapietro N, Beomonte Zobel B, Denaro V: Estimating the risk for symptomatic adjacent segment degeneration after lumbar fusion: analysis from a cohort of patients undergoing revision surgery. Eur Spine J 23 (Suppl 6):693-698, 2014

11. Dubousset J: Three-dimensional analysis of the scoliotic deformity, in Weinstein SL (ed): The Pediatric Spine: Principles and Practice. New York: Raven Press, 1994, pp 479-496

12. Ghiselli G, Wang JC, Hsu WK, Dawson EG: L5-S1 segment survivorship and clinical outcome analysis after L4-L5 isolated fusion. Spine (Phila Pa 1976) 28:1275-1280, 2003

13. Ghogawala Z, Dziura J, Butler WE, Dai F, Terrin N, Magge $\mathrm{SN}$, et al: Laminectomy plus fusion versus laminectomy alone for lumbar spondylolisthesis. N Engl J Med 374:14241434,2016

14. Gödde S, Fritsch E, Dienst M, Kohn D: Influence of cage geometry on sagittal alignment in instrumented posterior lumbar interbody fusion. Spine (Phila Pa 1976) 28:1693-1699, 2003

15. Gottfried ON, Daubs MD, Patel AA, Dailey AT, Brodke DS: Spinopelvic parameters in postfusion flatback deformity patients. Spine J 9:639-647, 2009

16. Jentzsch T, Geiger J, Bouaicha S, Slankamenac K, NguyenKim TDL, Werner CML: Increased pelvic incidence may lead to arthritis and sagittal orientation of the facet joints at the lower lumbar spine. BMC Med Imaging 13:34, 2013

17. Kumar MN, Jacquot F, Hall H: Long-term follow-up of functional outcomes and radiographic changes at adjacent levels following lumbar spine fusion for degenerative disc disease. Eur Spine J 10:309-313, 2001

18. Lai PL, Chen LH, Niu CC, Chen WJ: Effect of postoperative lumbar sagittal alignment on the development of adjacent instability. J Spinal Disord Tech 17:353-357, 2004

19. Legaye J, Duval-Beaupère G: Sagittal plane alignment of the spine and gravity: a radiological and clinical evaluation. Acta Orthop Belg 71:213-220, 2005

20. Legaye J, Duval-Beaupère G, Hecquet J, Marty C: Pelvic incidence: a fundamental pelvic parameter for three-dimensional regulation of spinal sagittal curves. Eur Spine $\mathbf{J}$ 7:99-103, 1998

21. O'Shaughnessy BA, Ondra SL: Measuring, preserving, and restoring sagittal spinal balance. Neurosurg Clin N Am 18:347-356, 2007

22. Rajnics P, Templier A, Skalli W, Lavaste F, Illes T: The importance of spinopelvic parameters in patients with lumbar disc lesions. Int Orthop 26:104-108, 2002

23. Rothenfluh DA, Mueller DA, Rothenfluh E, Min K: Pelvic incidence-lumbar lordosis mismatch predisposes to adjacent segment disease after lumbar spinal fusion. Eur Spine J 24:1251-1258, 2015
24. Roussouly P, Gollogly S, Berthonnaud E, Dimnet J: Classification of the normal variation in the sagittal alignment of the human lumbar spine and pelvis in the standing position. Spine (Phila Pa 1976) 30:346-353, 2005

25. Roussouly P, Nnadi C: Sagittal plane deformity: an overview of interpretation and management. Eur Spine J 19:18241836,2010

26. Schwab F, Patel A, Ungar B, Farcy JP, Lafage V: Adult spinal deformity-postoperative standing imbalance: how much can you tolerate? An overview of key parameters in assessing alignment and planning corrective surgery. Spine (Phila Pa 1976) 35:2224-2231, 2010

27. Van Royen BJ, De Gast A, Smit TH: Deformity planning for sagittal plane corrective osteotomies of the spine in ankylosing spondylitis. Eur Spine J 9:492-498, 2000

28. Van Royen BJ, Toussaint HM, Kingma I, Bot SD, Caspers $\mathrm{M}$, Harlaar J, et al: Accuracy of the sagittal vertical axis in a standing lateral radiograph as a measurement of balance in spinal deformities. Eur Spine J 7:408-412, 1998

29. Vaz G, Roussouly P, Berthonnaud E, Dimnet J: Sagittal morphology and equilibrium of pelvis and spine. Eur Spine J 11:80-87, 2002

30. Wang H, Ma L, Yang D, Wang T, Liu S, Yang S, et al: Incidence and risk factors of adjacent segment disease following posterior decompression and instrumented fusion for degenerative lumbar disorders. Medicine (Baltimore) 96:e6032, 2017

31. Weinstein JN, Lurie JD, Tosteson TD, Hanscom B, Tosteson AN, Blood EA, et al: Surgical versus nonsurgical treatment for lumbar degenerative spondylolisthesis. N Engl J Med 356:2257-2270, 2007

32. Yamasaki K, Hoshino M, Omori K, Igarashi H, Nemoto Y, Tsuruta T, et al: Risk factors of adjacent segment disease after transforaminal inter-body fusion for degenerative lumbar disease. Spine (Phila Pa 1976) 42:E86-E92, 2017

\section{Disclosures}

The authors report no conflict of interest concerning the materials or methods used in this study or the findings specified in this paper.

\section{Author Contributions}

Conception and design: WJ Chen. Acquisition of data: WJ Chen. Analysis and interpretation of data: Kao. Drafting the article: Kao. Reviewed submitted version of manuscript: Wang. Statistical analysis: IJ Chen. Study supervision: Hsieh.

\section{Correspondence}

Fu-Cheng Kao: Chang Gung Memorial Hospital, Taoyuan, Taiwan.afogi73@gmail.com. 